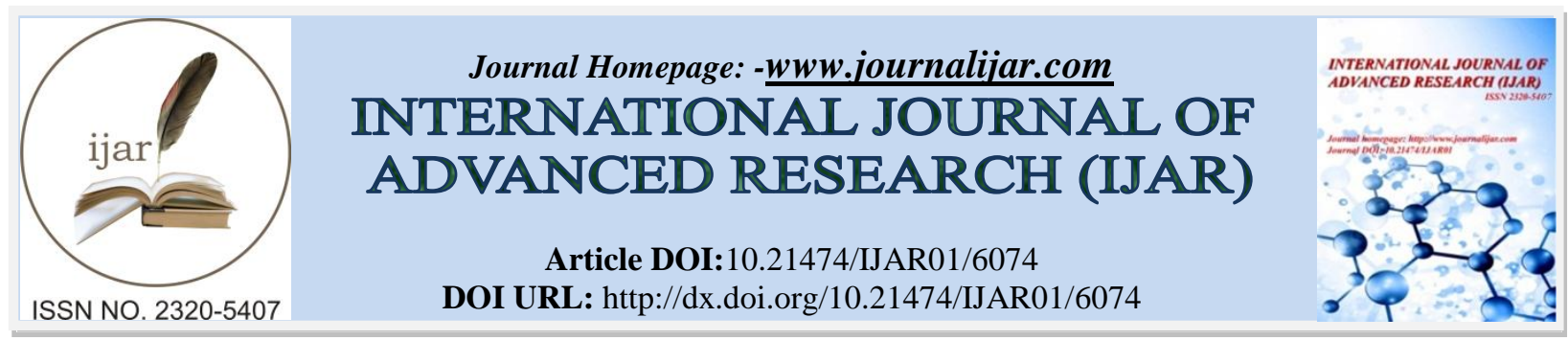

RESEARCH ARTICLE

\title{
A STUDY ON VARIATIONS OF ELECTRO CARDIOGRAM IN HEALTHY ADULTS.
}

\section{Y.Srinivas ${ }^{1}$, P.Srikanth, ${ }^{1}$ S.Srinivas ${ }^{2}$, Rama Krishna Reddy ${ }^{3}$, Shivasubramanyam ${ }^{4}$ and CRPS Krishna ${ }^{5}$.}

1. Asso. Prof of medicine (PinnamananeSiddhardtha Medical College Vijyawada, AP).

2. Prof of Medicine (FIMS Kadapa, AP).

3. Asst. Prof of Medicine (FIMS Kadapa,AP).

4. Asso. Prof. of Medicine (Kamineni Medical College, NarketPally, Telangana).

5. Asso. Prof Of medicine (Kamineni Medical College,NarketPally).

\section{Manuscript Info}

(.........................

Manuscript History

Received: 16 October 2017

Final Accepted: 18 November 2017

Published: December 2017

Key words:-

ECG

PR Interval

Brady Cardia, TachyCardia.

\section{Abstract}

Aims And Objectives:ToAnalys the pattern of Rate, plythm Axis, PRInterval, QRS Duration .QT Interval, ST Segment, of 12 Lead EGC and to note any Abnormalvariations and their relation to age \& to note normal variations also. This study was done in 3 centres.

Materials And Methods: 12 lead Electrocardiogram was taken for this study with $10 \mathrm{~mm}$ standardization.

Observations:The Common abnormalities like $\mathrm{T}$ wave inversion sinus Bradycardia, sinus tachycardia and RSR patterns were observed in our study.

Conclusion:Healthy individuals may have so many variations in ECG which were considered as with in normal limits. So understanding normal ECG and deviations in normal individuals is very important to interpret the disease states and treating them.

Copy Right, IJAR, 2017,. All rights reserved.

This study was done in 100 adults' males 77; Females 23 age group is between 20years and 40years. These subjects were evaluated clinically and ruled out the abnormalities of cardiac, pulmonary, endocrinal, CNS, and other systems and electrolyte abnormalities, which can have abnormal ECG, change. Subjects, who are having symptoms of cardiac, pulmonary were not included in this study.

\section{Introduction:-}

The normal heart beat is generated because of electrical activity and which is initiated in sino atrial node then spreads through the purkinge fibers to the myocardium. The same electrical activity passes to the surrounding Tissues. The intensity of electrical activity is decreases as distance increase from the heart (1) the Atria functions as a single electro physiological chamber - an electro physiologic unit. There is no electrical boundary between them and called as bi-atrial chamber. Similarly ventricles also called as bi-ventricular chamber

The electrical activity can be recorded from any part of the body, how every it needs to the augmented while recording ECG: AVR, AVF, AVL after recording ECG various intervals; and waves and their patterns have to be evaluated eg: QTC is longer during sleep but not nessarly abnormally prolonged (2). The aim of study is to know the different variations in normal individuals. 


\section{Material and Methods:-}

This study was conducted in 100 healthy individuals in those 23 were females 77 were males. Age group in between 20years and 40 years after thorough clinical examination of cardiac Respiratory, endocrinal CNS were Systems electrolytes were estimated, ECG's were taken. Then ECG in the following leads $\mathrm{L}_{1}$ L11 L111 AVR, AVL, AVF, V1 V2 V3 V4 V5 V6 were taken. COPD and addictions like smoking, Alcoholism which were known to alter the ECG were all excluded from this study. And History of coronary Heart Disease and congenital Heart diseases like ASD, VSD were excluded in the study. Thyroid function tests were done to exclude subclinical Hypothyroidism and sub clinical hyper thyroidism.

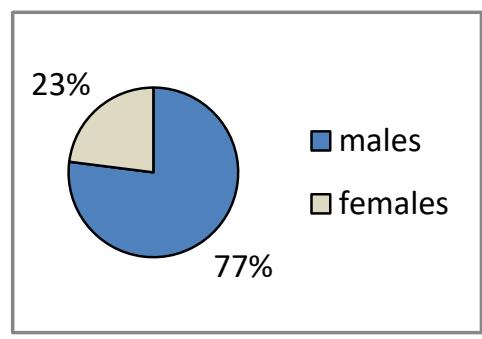

\section{Observation Of Results:-}

This study includes 100 healthy individuals out of which 77 were males, 23 were females. Minimum age is 20 years Maximum age is 40 years. The Heart rate varied between 54 and 106 beats per minute. And according to literature normal range of Heart rate is 60 to 100 beats/ Min less than 60 is called bradycandia and more than 100 is called tachycardia 56 were having Normal sinus rhythm(NSR) one interesting observation is higher heart rate in young individuals i.e. age between 20 years and 24 years.

One person is having Bradycardia. His age is 38 years 4 subjects were having tachycardia; their age is less than 30 years P-R interval variation is between $0.12 \mathrm{sec}$ to $0.24 \mathrm{sec}$. The normal range is $0.2 \mathrm{sec}$ to $0.20 \mathrm{sec}$. QRS duration varied between $0.08 \mathrm{sec}$ to $0.1 \mathrm{sec} 4$ persons are having in incomplete RBB which is normal most of the times. The electrical position of the heart which may or may not be related to anatomical position is determined by just 2 leads AVL and AVF based on above principles.

Among the waves ' $\mathrm{T}$ ' wave is the most common Wave which shows abnormal pattern Coving of ST segment is seen in 1 subject. And in case of chamber enlargement left ventricular hypertrophy in seen with in 4 subject - Right ventricular hypertrophy in seen in 1 subject

Table 1:-Sex distribution

\begin{tabular}{|l|l|}
\hline SEX & NUBMBER \\
\hline MALES & 77 \\
\hline FEMALE & 23 \\
\hline
\end{tabular}

Table 2:-Age distribution

\begin{tabular}{|l|l|l|}
\hline S.No & Age (in yrs) & No \\
\hline 1 & $20-25$ & 25 \\
\hline 2 & $25-35$ & 40 \\
\hline 3 & $35-40$ & 35 \\
\hline
\end{tabular}

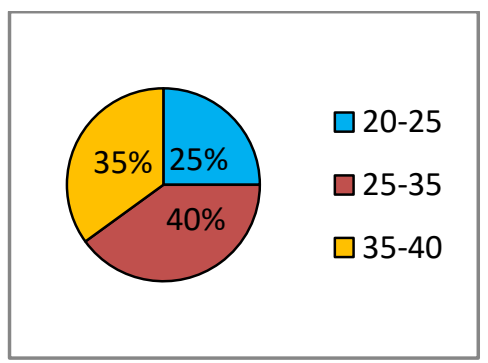

Table 3:-Variations of ECG 


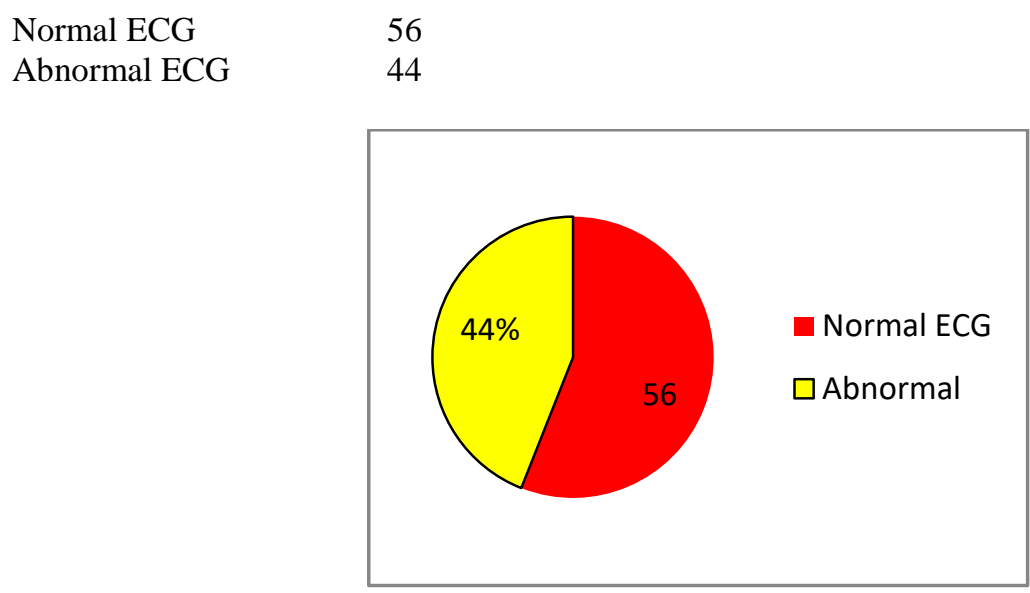

Table 4:-Various ECG Abnormalities

\begin{tabular}{lllr} 
S.No & ECG Abnormalities & \multicolumn{2}{c}{ Numbers } \\
1 & Sinus Arrhythymia & & 30 \\
2 & T Wave Invertion & 22 & \\
3 & Coving of ST Segment & 02 & \\
4 & Sinus Tachycardia & & 08 \\
5 & Sinus Bradycardia & & 01 \\
6 & RSR Pattren & 14 & \\
7 & LVH & 08 & \\
8 & RVH & 02 &
\end{tabular}

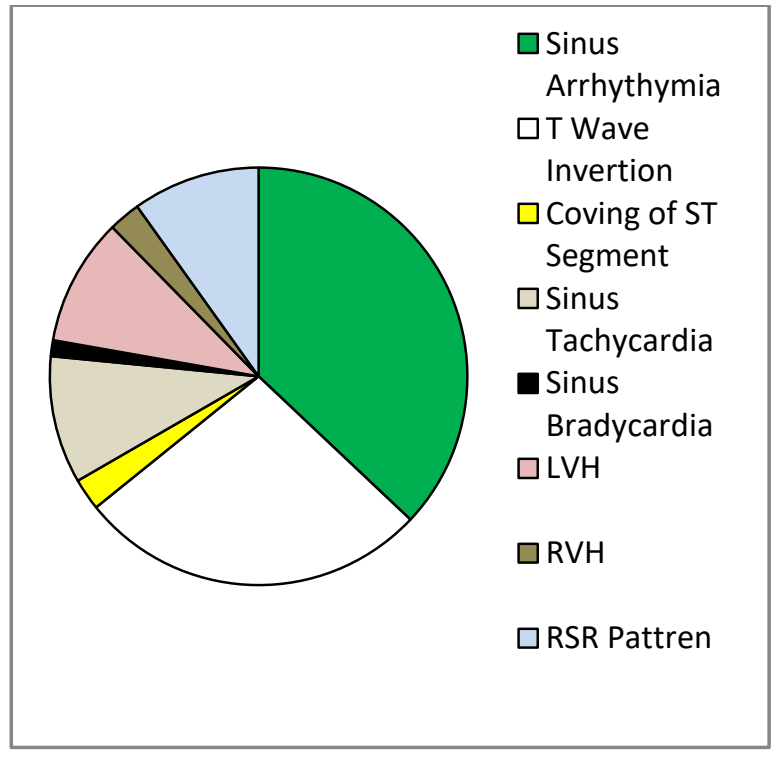

\section{Disussion:-}

ECG is recorded with the help of electrodes placed at different part of body (i.e. limb lead and chest leads). And it is a graphic representation of electrical activity of heart. This electrical activity can be recorded from various part of body. The ECG is cheap and best diagnostic investigation in diagnosing Acutemyocandialinfrction. We can diagnose Rate abnormalities rhythm abnormalities, chamber hypertrophy, electrolyte Abnormalities and other conditions. The present study is aimed to know certain abnormalities. Whether the ECG shows any abnormalities in normal individuals (2-6) are known to occur in normal individuals. They are benign like PVC'S (premature ventricular contractions and sometimes serious abnormalities which may be silent. Majority of ECG's in normal subjects. different patterns which falls within normal range (6-11). 
The common abnormalities are Bradycardia, Tachycardia RBBB and $\mathrm{T}$ wave inversion. So uderstanding normal variations are important to interprete in diagnosing diseases and treatment.

1. Lreoschmroth - An introduction to electro cardiography chapter 1. P. 141990 - edi.

2. Bron KF, prystisy E. Hegr J.J. \& zips. 1). P. (1983) prolgation of QT interval is man during sleep AM.jcadiat 52,55

3. Gerard Tortora\& Sandra Reynolds, Grabonslei, - principles of Anatomy and Physiology.

4. Goldmann: (ECG)Clinical electrocardiography

5. Dale Davis: ECG interpretation.

6. Fey WB. A History of the origin, and impact of electrocardiography, am journal of cardiol 1992,73,937-949

7. Harrison's principal of internal medicine

8. An introduction electrocardiography-Leo Schamroth

9. Understanding electrocardiography- PradipJ.Mehta

10. Atterhog, J.H and Loogna E.P;R Interval in relation to heart rate during exercise and the influence of posture and autonomic tone. J.Electrocardiol 1977;10,331

11. Lister J.W et al; Atrio ventricular condition in man; effect of rate, exercise, isoproterenol and atropine on the PR-interval A.M.J.Cardiol 1965;16,516.

12. Johnson R.L Averill K.H and Lamb L.F 1960 electrocardiographic Findings in 67, 375. Asymtomatic individuals part VI Right bundle branch block Am.J.Cardiol, 143. 